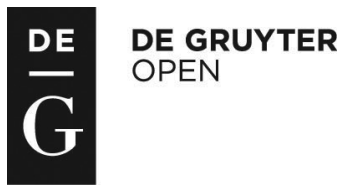

\title{
THE EFFECTS OF DIETARY WHEY LACTOSE AND LACTOBACILLUS AGILIS BACTERIA ON THE GROWTH PERFORMANCE, PHYSICOCHEMICAL CONDITIONS OF THE DIGESTIVE TRACT AND THE CAECAL MICROBIAL ECOLOGY OF BROILER CHICKENS*
}

\author{
Witold Szczurek $^{1 \bullet}$, Mohamed Nabil Alloui1 ${ }^{1}$, Damian Józefiak ${ }^{2}$ \\ ${ }^{1}$ Department of Animal Nutrition and Feed Science, National Research Institute of Animal Production, \\ 32-083 Balice n. Kraków, Poland \\ ${ }^{2}$ Department of Animal Nutrition and Feed Management, Poznań University of Life Sciences, \\ Wołyńska 33, 60-637 Poznań, Poland \\ •Corresponding author: witold.szczurek@izoo.krakow.pl
}

\begin{abstract}
The principal goal of this study was to assess the responses of broiler chickens raised on floor litter to the $2 \%$ dietary level of lactose (LAC) originating from dried whey fed in combination with live culture of Lactobacillus agilis bacteria ( 90 million cells/kg diet) in terms of the performance and basic postslaughter parameters, the lumen $\mathrm{pH}$ in some alimentary tract segments, concentration of volatile fatty acids (VFA) in the total (T) and undissociated (UD) forms and count of selected microbial populations in the caeca determined by fluorescent in-situ hybridisation (FISH). A parallel aim was to evaluate the outcomes from the combined supplementation in comparison with feeding of LAC and the $L$. agilis bacteria as separate dietary supplements. Six hundred and forty Ross 308 chickens were placed in 16 floor pens ( 40 birds per pen having equal sex ratio) and were provided with free access to the feed (a mash maize-wheat-soybean meal-based diet) and water. Dietary treatments provided from day 8 to 42 of age were: LAC-free basal diet (CON), LAC-containing diet (CON + LAC), LAC-free diet with the addition of $L$. agilis (CON + BAC) and LAC-containing diet with addition of L. agilis (CON + LAC + BAC). The LAC supplementation caused significant decreases in the luminal pH of the crop, ileum and caeca, and the addition of the $L$. agilis bacteria reduced the $\mathrm{pH}$ in the crop and caeca. The overall concentration of total $(T)$ volatile fatty acids was higher in the caeca of broilers receiving the LAC-containing diets. Both the LAC and the BAC supplements, independently from one another, resulted in significantly greater caecal levels of UD acetate, propionate and butyrate. The FISH analysis revealed that counts of Bacteroides sp./Prevotella sp. group were higher after the inclusion of LAC in the feed. All three dietary supplementations significantly reduced the total counts of the family Enterobacteriaceae and decreased the number of naturally occurring $C$. perfringens bacteria compared with the basal control diet (CON). Neither LAC inclusion nor BAC addition to the diet affected the counts of the Clostridium coccoides/Eubacterium rectale group. The synergistic effects of the simultaneous supplementation of LAC and $L$. agilis were found on the T butyrate concentration and on $C$. perfringens and the Enterobacteriaceae counts. No improvements in the body weight gains and post-slaughter traits were observed due to uncombined and combined supplementation with $2 \%$ LAC and L. agilis,
\end{abstract}

*This work was supported from the National Research Institute of Animal statutory activity, Research Project No. 2257.1. 
indicating that the shifts in composition of the caecal microbiota toward a healthier composition by using these additives were not large enough to create the positive growth rate and processing yields responses in broilers maintained in a litter-floor environment.

Key words: lactose, Lactobacillus agilis, pH, VFA, caecal microflora, in situ hybridisation, 16S rRNA, performance, broilers

Concerns about the losses in animal performance coupled with an EU-wide ban on the use of in-feed antibiotic growth promoters (AGP) have led to an increase in research on alternative products. As a consequence, a number of possible alternatives to AGP have been investigated, especially prebiotics and probiotics, to evaluate the usefulness of their incorporation in feed as causative factors for the reduction of enteropathogens and better growth or egg production in poultry (Alloui et al., 2013; Adhikari and Kim, 2017).

In animal nutrition 'prebiotics' are usually defined as feed ingredients that escape digestion in the upper part of the alimentary tract and selectively favour the multiplication or metabolic activity of a specific fraction of the intestinal microbiota. In the conventional and alternative poultry production systems, the use of fermentable oligosaccharides as prebiotic supplements is gaining in popularity (Ricke, 2015). Lactose, a disaccharide present in the milk of all mammals and the major component of dried bovine whey (whey powder) is not digested to any appreciable extent in the avian small intestine, so it can reach the lower intestinal tract and potentially act as a prebiotic. Within the literature some evidence exists demonstrating that supplemental lactose in broiler chickens may promote the growth of beneficial lactose-utilising bacteria that compete with enteropathogens and/or suppression of pathogens by the lactose can be ascribed to an increased acidity of the intestinal contents resulting from fermentation of this disaccharide (Rehman et al., 2009). Recent data from our laboratory have also shown that dietary inclusion of $1 \%$ or $2 \%$ lactose sourced from dried whey results in consistent increases in the body weight gain endpoints of broilers raised to market age in battery cages (Alloui and Szczurek, 2017). The term 'probiotic' is used in animal nutrition to describe feed additives consisting of single or mixed cultures of living microorganisms which can beneficially affect the host by improving the properties of the indigenous microbiota (Fuller, 1989). The predominant group of probiotic bacteria are bacilli of the Lactobacillus genus - perceived to be the most adequate microorganisms used to provide health benefits and anti-pathogenic action when consumed (Wyszyńska et al., 2015). Products representing a synergistic blend of prebiotics and probiotics are defined as synbiotics. Some studies have shown the positive impact of this synergy on the caecal beneficial bacteria and its role in improving the growth performance of broiler chickens (Mookiah et al., 2014).

It appears that one of the important strategies to obtaining more pronounced benefits from lactose as fermentable prebiotic carbohydrate in broiler diets is to use it in conjunction with viable lactobacilli. There is evidence that dietary lactose with the co-addition of a Lactobacillus spp.-based preparation can be more advantageous in improving the performance of growing turkeys (Vicente et al., 2007). However, 
to our knowledge very little reliable information has been gathered about such an approach with respect to broiler chickens. Therefore, the primary objective of this study was to investigate the responses of broiler chickens raised on floor litter to the dietary cosupplementation with lactose, originating from dried whey, and chosen Lactobacillus species, specifically Lactobacillus agilis. A parallel aim included the comparative evaluation of outcomes from the combined and separate supplementation of the diets with whey lactose and the L. agilis bacteria. The productive performance endpoints and basic carcass parameters, the luminal $\mathrm{pH}$ in some digestive tract segments, concentration of volatile fatty acids in the total and undissociated forms and count of selected microbial populations in the caecal contents determined by fluorescent in-situ hybridisation were considered as the main response criteria.

\section{Material and methods}

All experimental procedures used throughout this study were reviewed and approved by the II Local Ethics Committee for Animal Experimentation in Kraków.

\section{Source of dietary lactose}

Lactose was provided from commercial dried whey (DW) included in the feed to attain the pre-planned lactose level. According to the certificate of analysis issued by the manufacturer (Dairy Cooperative Ryki, Poland), the proximate nutrients and lactose (LAC) content of the DW was as follows: dry matter (DM), 97.20\% as-fed; crude protein $(\mathrm{N} \times 6.38), 11.93 \%$ of DM; ether extract, $0.51 \%$ of DM; crude ash, 7.82 of DM; LAC, $79.73 \%$ of DM.

\section{Microbiological product used as feed additive}

The microbial preparation was based on a naturally occurring single strain of Lactobacillus agilis which was isolated from the excreta of healthy free-range chickens and identified with sequencing of $16 \mathrm{~S}$ rRNA gene technique by the Institute of Agricultural and Food Biotechnology (IAFB) in Warsaw (Poland). According to the IAFB, the preparation contained $7.5 \times 108$ viable cells of $L$. agilis per $\mathrm{g}$.

\section{Birds, housing and feeding}

The experiment was carried out on 640 broiler chickens (Ross 308) with sex ratio 1:1. The chicks were hatched and feather-sexed at a local commercial hatchery. Upon arrival (day 1 of age), forty chicks per each sex were randomly selected and individually weighed (resulting mean body mass was $37.3 \pm 0.6 \mathrm{~g}$ ). Immediately after weighing the selected birds, all 640 chicks were transferred to an environmentally controlled facility and placed at random in 16 floor pens (40 birds per pen having equal sex ratio) with feed and water available ad libitum. Each pen $(1.8 \times 1.7 \mathrm{~m})$ was equipped with a pan (diameter $30 \mathrm{~cm}$ ) and a large capacity hanging feeder for providing feed, and a bell drinker and trough waterer ( $3 \mathrm{~cm} /$ bird) for providing water to birds during days 1-21 and 22-42 of life, respectively. The chickens were housed on wood shavings litter in thermal and 
lighting conditions recommended by the breeder (Aviagen, 2014), and from day 1 to 42 were fed on non-medicated (except for anticoccidials) mash diets based on maize, wheat and soybean meal. The pre-experimental period of rearing lasted 7 days (day 1 to 7), during which the chicks received the same prestarter type diet. Beginning at day 8 , all the birds were fed starter type diets, and from day 22 of life they were switched to the grower type diets (Table 1). Throughout the rearing period the chickens were continuously observed for health status and mortality.

Table 1. Composition and nutrient content of the diets fed to growing chickens $(\mathrm{g} / \mathrm{kg})$

\begin{tabular}{|c|c|c|c|c|c|}
\hline \multirow[b]{2}{*}{ Item } & \multirow[b]{2}{*}{ Pre-starter } & \multicolumn{2}{|c|}{ Starter } & \multicolumn{2}{|c|}{ Grower } \\
\hline & & $\begin{array}{l}\text { basal } \\
\mathrm{CON}\end{array}$ & $\begin{array}{l}\text { with lactose }^{1} \\
\text { CON+LAC }\end{array}$ & $\begin{array}{l}\text { basal } \\
\mathrm{CON}\end{array}$ & $\begin{array}{l}\text { with lactose } \\
\text { CON+LAC }\end{array}$ \\
\hline \multicolumn{6}{|l|}{ Ingredients } \\
\hline maize & 395.0 & 400.3 & 359.5 & 373.4 & 332.6 \\
\hline wheat & 140.0 & 170.0 & 170.0 & 230.0 & 230.0 \\
\hline soybean meal $(46.8 \% \mathrm{CP})$ & 395.0 & 350.0 & 350.0 & 300.0 & 300.0 \\
\hline soybean oil & 25.0 & 35.0 & 50.0 & 55.0 & 70.0 \\
\hline $\mathrm{Ca}\left(\mathrm{H}_{2} \mathrm{PO}_{4}\right)_{2}$ & 18.0 & 18.0 & 18.0 & 16.0 & 16.0 \\
\hline limestone & 16.0 & 16.0 & 16.0 & 15.0 & 15.0 \\
\hline $\mathrm{NaCl}$ & 3.0 & 3.0 & 3.0 & 3.0 & 3.0 \\
\hline premix, ${ }^{2,3}$ & $5.0^{2}$ & $5.0^{2}$ & $5.0^{2}$ & $5.0^{3}$ & $5.0^{3}$ \\
\hline L-lys $\mathrm{HCl}(79 \%)$ & 1.5 & 1.3 & 1.3 & 1.2 & 1.2 \\
\hline DL-met $(99 \%)$ & 1.5 & 1.4 & 1.4 & 1.4 & 1.4 \\
\hline dried whey (DW) & - & - & 25.8 & - & 25.8 \\
\hline \multicolumn{6}{|l|}{ Formulated value ${ }^{4}$} \\
\hline $\mathrm{ME}(\mathrm{MJ} / \mathrm{kg})$ & 12.52 & 12.80 & 12.78 & 13.41 & 13.40 \\
\hline crude protein $(\mathrm{N} \times 6.25)$ & 239 & 222 & 221 & 203 & 202 \\
\hline lysine (total) & 14.2 & 12.8 & 12.7 & 11.4 & 11.3 \\
\hline methionine (total) & 5.2 & 4.9 & 4.8 & 4.5 & 4.5 \\
\hline threonine (total) & 9.1 & 8.3 & 8.2 & 7.5 & 7.4 \\
\hline $\mathrm{Ca}$ & 11.4 & 11.2 & 11.2 & 10.3 & 10.3 \\
\hline $\mathrm{P}$ available & 5.4 & 5.3 & 5.3 & 4.8 & 4.8 \\
\hline
\end{tabular}

${ }^{1}$ Lactose supplied by dried whey (DW).

${ }^{2,3}$ Vitamin-trace mineral premix provided per kilogram of diet: ${ }^{2}$ vit. A 13500 IU; vit. D 3600 IU; mg: vit. E 45 ; vit. $\mathrm{K} 3$; vit. $\mathrm{B}_{1} 3.25$; vit. $\mathrm{B}_{2} 7.5$; vit. $\mathrm{B}_{6} 5$; vit. $\mathrm{B}_{12} 0.03$; biotin 0.15 ; folic acid 1.5 ; nicotinic acid 45 ; calcium pantothenate 15; choline chloride 600; Fe 67.5; Zn 75; Mn 100; Cu 17.5; I 1; Se 0.28; Co 0.4; coccidiostat (diclazuril) $1 ;{ }^{3}$ vit. A 12000 IU; vit. D 3250 IU; mg: vit. E 40; vit. K 2.25; vit. B 2; vit. B 7.25; vit. B $_{6} 4.25$; vit. B 0.03 ; biotin 0.1 ; folic acid 1; nicotinic acid 40; calcium pantothenate 12; choline chloride 450; Fe 65; $\mathrm{Zn} \mathrm{65;} \mathrm{Mn}$ 100; Cu 15; I 0.8; Se 0.25; Co 0.4; coccidiostat (semduramycin) 25.

${ }^{4}$ Calculated on the basis of chemical analysis of soybean meal and from tabular data on proximate composition for the remaining feed materials (Smulikowska and Rutkowski, 2005), energy value - using formulas of The European Table of Energy Values for Poultry Feedstuffs (1989), 3rd ed., WPSA, Wageningen. The energy contribution from DW inclusion was considered insignificant.

\section{Experimental design and treatments}

A completely randomised design in a $2 \times 2$ factorial arrangement was used for this experiment; factors were the absence or presence of whey lactose (LAC) in the diet, and with or without Lactobacillus agilis bacteria supplement (BAC). After 7 days of the 
pre-experimental period, on day 8 , the birds were randomly assigned to four treatment groups, such that there were 4 replicate pens of chickens per group, with 40 birds in each pen. The experimental treatments were as follows: lactose-free basal diet (CON); whey lactose-containing diet (CON + LAC); basal diet supplemented with L. agilis bacteria $(\mathrm{CON}+\mathrm{BAC})$; whey lactose-containing diet supplemented with L. agilis bacteria $(\mathrm{CON}+\mathrm{LAC}+\mathrm{BAC})$. Based on the results of our previous experiment (Alloui and Szczurek, 2017), lactose inclusion level was $2 \%$ in the starter and grower type diets. To attain this LAC level in the feed, dried whey (DW) was added in amount of $25.8 \mathrm{~g} / \mathrm{kg}$ of diet replacing maize on an as-fed (wt/wt) basis. In order to keep the diets isoenergetic after withdrawing a portion of maize, metabolisable energy was adjusted by increasing amounts of soybean oil. The bacterial preparation of $L$. agilis was included in the diets 'on top' in amount of $0.12 \mathrm{~g} / \mathrm{kg}$ to provide 90 million bacterial cells $/ \mathrm{kg}$ of feed.

\section{Measurements and collection of samples}

The chickens in each pen were group weighed (by tens) at 7:00 a.m. on day 8 (before they were designated to treatment groups) and at days 21 and 42 of life. Feed intake (FI) was recorded on a pen basis at weekly intervals. Body weight gains (BWG) were calculated for the entire experimental period (days 8 to 42). Feed conversion ratio (FCR) values were corrected for the weight of dead and culled birds. At day 34, eight chickens were selected in a random manner from each pen within treatment in order to collect their excreta. These birds were transferred for two days into 16 group cages equipped with dropping trays placed under the wire mesh floor. During this period the chickens were allowed to consume their respective diets and the first day served as an acclimatisation phase. Excreta collected from each cage in the middle of the second day were homogenised and stored at $-20^{\circ} \mathrm{C}$ prior to analysis for dry matter, and the chickens were transferred back to the respective floor pens. After weighing the chickens on day 42 , 6 males and 6 females were chosen at random from each treatment group. The birds were labelled, individually weighed and killed by cervical dislocation in groups of twelve chickens at $20 \mathrm{~min}$ intervals. After bleeding, the abdomens of the non-scalded/plucked carcasses were opened and the entire alimentary tract was removed. Subsequently, the $\mathrm{pH}$-value of the contents in the crop, ileal section of the small intestine and the left and right caeca was determined on site using a CyberScan ${ }^{\circledR}$ digital $\mathrm{pH}$ meter (Eutech Instruments, Singapore). Further, the caecal contents of 6 mixed-sex chickens (per 12 selected from each treatment group) were taken, placed into plastic containers and stored at $-20^{\circ} \mathrm{C}$ for the following analysis of volatile fatty acids (VFA). On the completion of the experiment (day 43), 48 broilers were processed to evaluate carcass characteristics and the weight of selected organs. The day before processing, 12 birds with the LBW close to the group average (sex ratio 1:1) were chosen from each dietary treatment. The birds were leg banded, placed in metal cages in a ventilated room and deprived of feed for $12 \mathrm{~h}$ until processing the next day. The chickens were weighed before slaughter and dispatched by cervical dislocation in groups of 12 broilers. After bleeding for $2 \mathrm{~min}$, the birds were defeathered and their carcasses were manually eviscerated. During evisceration the liver, spleen and bursa of Fabricius were carefully excised, rinsed in deionised water, allowed to drip-dry and weighed. The relative organ weights (as a \% of LBW) were then calculated. The empty carcasses without the feet and heads were air-chilled 
overnight at $4^{\circ} \mathrm{C}$ and weighed. The carcasses were then dissected to measure the mass of boneless and skinless left-side breast and left leg muscles and abdominal fat. The percentage carcass recovery, muscle yields and abdominal fat deposition were then calculated. Additionally, on day 43, twenty birds (sex ratio 1:1) were randomly selected from each treatment for post-mortem sampling of the caecal contents. The chickens were leg banded, dispatched according to the method described above and processed without defeathering. The abdominal cavity was opened and both caeca were excised, and then chyme was aseptically collected. The caecal contents from 4 mixed-sex birds within a treatment were pooled to yield 5 replicate samples per treatment. These samples were immediately placed in zip-lock sterile polyethylene bags packed with dry ice (ca. $-80^{\circ} \mathrm{C}$ ) and shipped to the microbiological laboratory for bacterial ecosystem analysis.

\section{Chemical analyses and calculations}

All the compositional analyses were performed in duplicate. The concentrations of proximate nutrients and amino acids in soybean meal (for formulation purposes) and dry matter content of the excreta were analysed according to AOAC International (2000) procedures. For the determination of the total VFA, a $2 \mathrm{~g}$ sample of thawed caecal chyme was filtered through absorbent wool on a laboratory vacuum station, rinsed, and the filtrate was diluted with deionised water to the final volume of $50 \mathrm{ml}$. Then, $5 \mathrm{ml}$ of that solution was mixed with $1 \mathrm{ml}$ of $24 \%$ metaphosphoric acid, incubated for $30 \mathrm{~min}$, and centrifuged at 13,000 g for $7 \mathrm{~min}$. The supernatant was analysed with a gas chromatograph (Varian Inc., Walnut Creek, USA, Model 3400) equipped with FID and a Zebron ZB-Wax capillary column (30 m long, $0.53 \mathrm{~mm}$ i.d., $1 \mu \mathrm{m}$ film thickness; Phenomenex Inc., Torrance, USA). The concentration of undissociated VFA were calculated from the total acid contents with the Henderson-Hasselbalch equation:

$$
p H=p K a+\log 10[A-] /[H A]
$$

where: $A$ is dissociated acids and $H A$ is undissociated acids; with measured caecal $\mathrm{pH}$, the $\mathrm{pKa}$ of each acid, and the total acid concentration as determined by gas chromatography. The respective $p K a$ values used in calculating the concentration of undissociated acid present were: acetic 4.76 , propionic 4.88 , isobutyric 4.85 , and butyric 4.82 .

\section{Microbial community analysis}

The identification and enumeration of caecal bacteria was performed by fluorescent in-situ hybridisation (FISH) technique with group specific, 16S rRNA-targeted oligonucleotide probes. After thawing, the 3-g caecal chyme samples were mixed with $37 \mathrm{ml}$ of phosphate-buffered saline (PBS). The mixture was vortexed with sterile glass beads for $3 \mathrm{~min}$ and centrifuged ( $500 \mathrm{~g}$ for $1 \mathrm{~min}$ ) to remove debris. Samples were fixed overnight at $4^{\circ} \mathrm{C}$ with paraformaldehyde/PBS mixture (3\% wt/vol), then resuspended in $50 \%(\mathrm{vol} / \mathrm{vol})$ ethanol/PBS and stored at $-20^{\circ} \mathrm{C}$. Portion of $100 \mu \mathrm{l}$ of the preserved caecal contents was diluted in PBS and pipetted onto $0.22 \mu \mathrm{m}$ pore size polycarbonate filters. After vacuuming, the filters were transferred on cellulose discs for dehydration in an ethanol series (50, 80 and 96\%, 3 min each). Hybridisations were carried out in $50 \mu$ l of hybridisation 
buffer [0.9 M NaCl, 20 mmol Tris/HCl (pH 7.2), 0.01\% sodium dodecylsulphate (SDS)] containing the oligonucleotides probes selected from the literature (Table 2). Samples hybridised with each probe were a set of 10 parallel preparations. After hybridisation, the filters were washed with washing buffer $[20 \mathrm{mmol}$ Tris/ $\mathrm{HCl}$ ( $\mathrm{pH} 7.2), 0.01 \%$ SDS, $5 \mathrm{mmol}$ ethylenediamine tetraacetic acid (EDTA)] for $20 \mathrm{~min}$ at $48^{\circ} \mathrm{C}$. The filters were rinsed gently in deionised water, air-dried, and mounted on object glasses with VectaShield anti-fading agent (Vector Laboratories Ltd., Peterborough, UK, no. H-1000). The filters were kept at $4^{\circ} \mathrm{C}$ in the dark until visualised using epifluorescence microscope (Olympus Corp., Tokyo, Japan, BH-2 model) and the obtained fluorescent images were stored electronically.

Table 2. Oligonucleotide probes used in the FISH procedure

\begin{tabular}{l|c|lll}
\hline \multicolumn{1}{c|}{ Target } & \multicolumn{1}{c|}{ Probe } & \multicolumn{1}{c}{ Sequence (5' to 3') } & \multicolumn{1}{c}{ Reference } \\
\hline $\begin{array}{l}\text { Bacteroides-Prevotella } \text { cluster } \\
\text { Clostridium } \text { coccoides- }\end{array}$ & Bac303 & CCAATGTGGGGGACCTT & Manz et al. (1993) \\
$\begin{array}{l}\text { Eubacterium rectale } \text { cluster } \\
\text { Enterobacteriaceae }\end{array}$ & Erec482 & GCTTCTTAGTCARGTACCG & Franks et al. (1998) \\
Clostridium perfringens & Cperf191 & CTTTTGCAACCCACT & Sghir et al. (2000) \\
\hline
\end{tabular}

\section{Statistical analysis}

For the growth performance parameters, pen means were considered as the experimental units. Because of non-normal distribution, mortality data were subjected to logarithmic transformation: $x^{\prime}=\log (x+2)$ before analysis and then converted back to the percentage scale. When analysing post-slaughter and physiochemical data, the experimental units were individual birds of both sexes. To ensure homogeneity of variance between the treatment groups, all the FISH microbiological data were analysed using the $\log _{10}$ transformations. Statistical analysis of the collected data was performed with the GLM procedure of Statistica ${ }^{\circledR} 12$ package (StatSoft Inc. Tulsa, OK, USA), using two-way ANOVA according to the following general model:

$$
Y i j=\mu+\alpha i+\beta j+(\alpha \beta) i j+\delta i j
$$

where: Yij-dependent variable, $\mu$ - overall mean, $\alpha i$ - effect of the presence of whey lactose in the diet, $\beta j$ - effect of $L$. agilis bacteria addition to the diet, $(\alpha \beta) i j$-interaction between lactose presence and bacteria addition, $\delta i j$ - residual error term.

When the overall effect was significant (P less than 0.05) dietary treatment mean separation was accomplished using Tukey's HSD test for the growth performance and post-slaughter parameters or with Fisher's LSD post-hoc test for the rest of dependent variables. The level of significance tested in each instance was $\mathrm{P}<0.05$. To characterise the variability of each parameter and certainty of the estimation of the mean, pooled standard errors of the mean (SEM) were used. Root mean square errors (RMSE) were also used to illustrate the differences between the values predicted by a model and the values actually observed. 


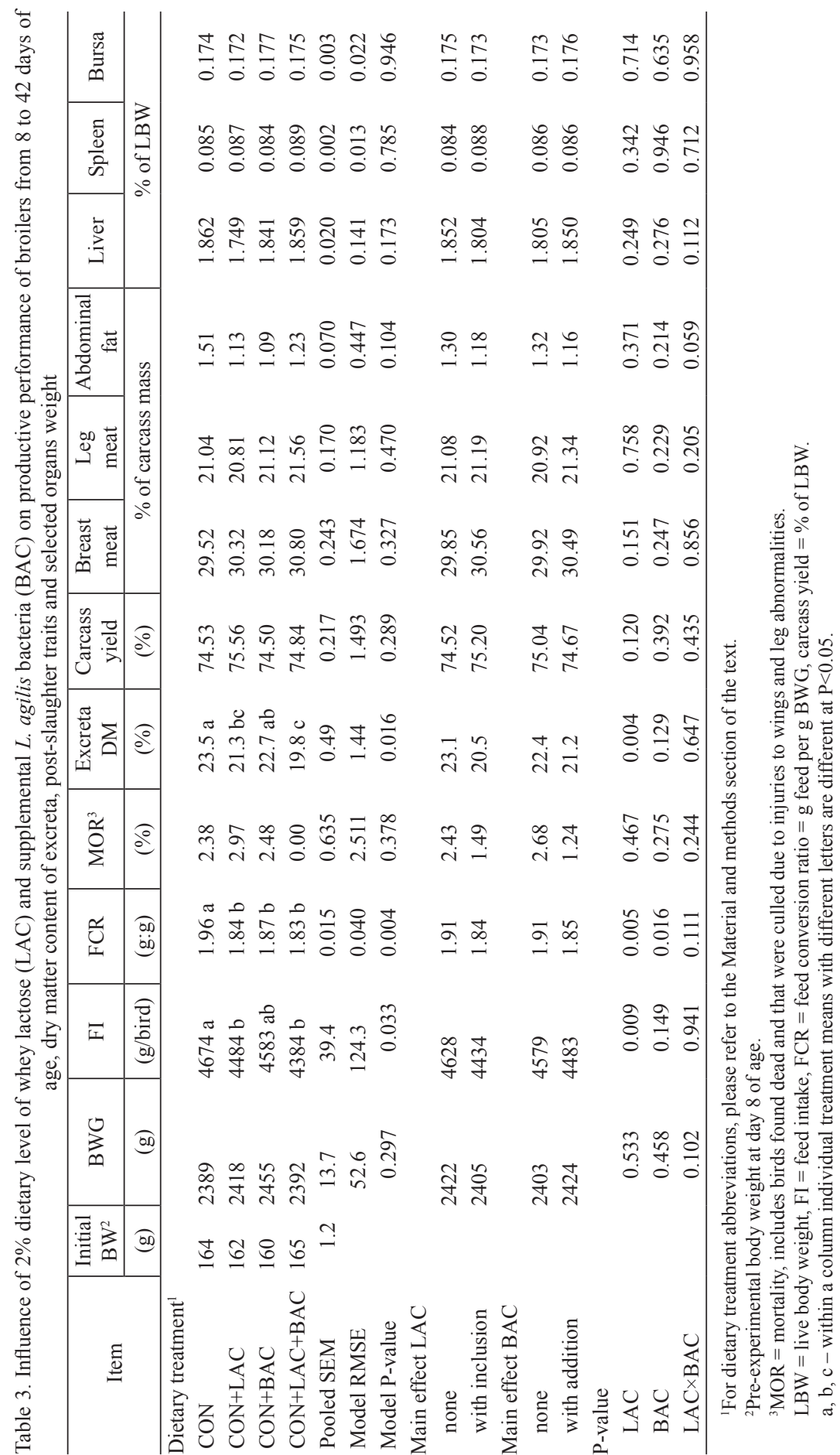




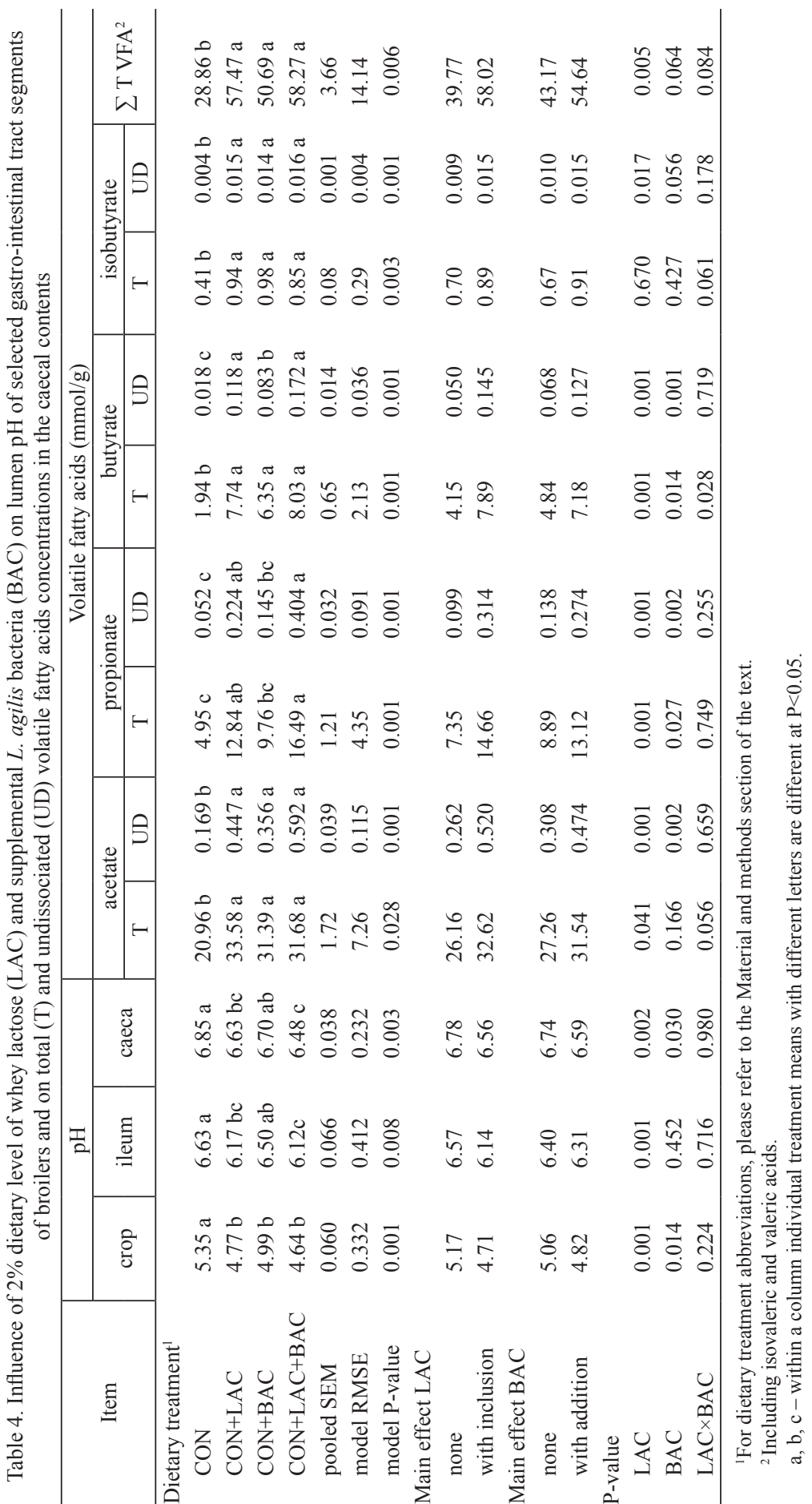




\section{Results}

The inclusion of $2 \%$ whey lactose (+ LAC) in the basal (CON) diet as well as the addition of $L$. agilis ( + BAC), or a combination of these treatments, did not significantly affect the BWG of chickens during the experimental period (Table 3). The FI was significantly influenced by individual dietary treatments, with a lower feed consumption in birds fed the diets containing LAC $(\mathrm{P}=0.009)$. The feed efficiency from day 8 to 42 was improved $(\mathrm{P}<0.05)$ in all supplemented groups compared with the CON treatment, and these observations were supported by the significant independent (interaction not significant) main effects of both the LAC and BAC supplements. Mortality defined as live culling and death rate throughout the experimental period was moderate $(1.96 \%$ on average) and was not significantly associated with any particular treatment. The presence of LAC in the diet decreased the excreta dry matter percentage with an overall effect significant at $\mathrm{P}=0.004$ and with significant differences detected between individual treatments $\mathrm{CON}$ vs. $\mathrm{CON}+\mathrm{LAC}$ and $\mathrm{CON}$ vs. $\mathrm{CON}+\mathrm{LAC}+\mathrm{BAC}$. There were no two-way LAC $\times$ BAC interactions $(\mathrm{P}>0.05)$ for the BWG, FI, FCR, mortality and the excreta moisture content. Dietary supplementation with the $2 \%$ whey lactose, L. agilis bacteria or with a combination of both additives did not alter any trait related to the carcass quality and the weight of selected organs of mixed-sex broilers. The overall values for the main effects (with vs without LAC or BAC) as well as the individual treatment means for carcass yield, breast and leg meat percentages, abdominal fat deposition and the relative weights of liver, spleen and bursa were statistically similar $(\mathrm{P}>0.05)$. No significant interactions were detected between the LAC presence and dietary L. agilis addition for the analysed slaughter characteristics and organ weights (Table 3). The effects of LAC and BAC supplementations on intraluminal $\mathrm{pH}$ in selected segments of the chicken alimentary tract and on the caecal total (T) and undissociated (UD) VFA concentrations are reported in Table 4. The LAC supplementation caused the significant overall decreases in the $\mathrm{pH}$ of crop $(\mathrm{P}=0.0001)$, ileal $(\mathrm{P}=0.001)$ and caecal $(\mathrm{P}=0.002)$ contents, whereas the supplemental L. agilis bacteria reduced the $\mathrm{pH}$ in the crop and caeca $(\mathrm{P}=0.030-0.014)$. However, no significant interactions between the main effects of LAC and BAC were computed. At the age of 42 days the broilers receiving the lactose-containing diets (main effect LAC) had significantly more $\mathrm{T}$ acetate, propionate and butyrate and a higher overall sum of T-VFA in their caeca. In general, the chickens provided the bacterial preparation (main effect BAC) had significantly larger concentrations of $\mathrm{T}$ propionate $(\mathrm{P}=0.027)$ and butyrate $(\mathrm{P}=0.014)$ and a numerically higher overall concentration of T-VFA $(\mathrm{P}=0.064)$. Regarding the caecal concentrations of total butyrate, the positive response to the LAC supplementation was strengthened by the inclusion of $L$. agilis preparation, as demonstrated by the significant LAC $\times$ BAC interaction. Calculation of the $\mathrm{pH}$-corrected values for undissociated VFA concentrations indicated that supplemental LAC caused the significantly higher production of UD acetic, propionic, butyric and isobutyric acids in the caeca. The dietary inclusion of the L. agilis preparation (main effect BAC) resulted in significant increases in the concentration of UD acetic, propionic and butyric acids, and this was numerically evident for the combined treatment with whey lactose $(\mathrm{CON}+\mathrm{LAC}+\mathrm{BAC})$. The results of the bacterial counts in the caeca obtained by FISH analysis are shown in Table 5. Neither LAC 
inclusion nor BAC addition to the diet affected the Clostridium coccoides/Eubacterium rectale counts in the caecal contents. The caecal counts of Bacteroides sp./Prevotella $s p$. were higher in the birds fed the LAC-containing diets $(\mathrm{P}=0.001)$, while the dietary BAC generally decreased rates of these organisms $(\mathrm{P}=0.002)$. As a consequence, no difference among individual groups $\mathrm{CON}$ vs. $\mathrm{CON}+\mathrm{LAC}+\mathrm{BAC}$ was found for these genera $(\mathrm{P}>0.05)$. The considerable decreases $(\mathrm{P}=0.001)$ in the caecal Enterobacteriaceae and Clostridium perfringens populations were noted as the overall effects of the LAC or BAC presence in the diets, with a significant LAC $\times$ BAC interaction for the $C$. perfringens count. The between-group comparisons showed that Enterobacteriaceae organisms and the Clostridium perfringens bacteria were the least numerous in the caeca of the chickens fed with the combination of both supplements $(\mathrm{P}<0.05)$.

Table 5. Influence of 2\% dietary level of whey lactose (LAC) and supplemental L. agilis bacteria (BAC) on selected microbial populations in the caecal contents $\left(\log _{10} \mathrm{cfu} / \mathrm{g}\right)$ estimated by fluorescent in-situ hybridisation (FISH) of single bacterial cells

\begin{tabular}{|c|c|c|c|c|}
\hline Item & \begin{tabular}{|c|} 
Bacteroides sp./ \\
Prevotella sp.
\end{tabular} & $\begin{array}{c}\text { Clostridium coccoides/ } \\
\text { Eubacterium rectale }\end{array}$ & Enterobacteriaceae & $\begin{array}{l}\text { Clostridium } \\
\text { perfringens }\end{array}$ \\
\hline \multicolumn{5}{|l|}{ Dietary treatment $^{1}$} \\
\hline $\mathrm{CON}$ & $8.75 \mathrm{bc}$ & 9.06 & $8.61 \mathrm{a}$ & $8.70 \mathrm{a}$ \\
\hline $\mathrm{CON}+\mathrm{LAC}$ & $9.01 \mathrm{a}$ & 9.05 & $8.24 \mathrm{~b}$ & $7.96 \mathrm{~b}$ \\
\hline $\mathrm{CON}+\mathrm{BAC}$ & $8.69 \mathrm{c}$ & 9.16 & $8.06 \mathrm{~b}$ & $7.99 \mathrm{~b}$ \\
\hline $\mathrm{CON}+\mathrm{LAC}+\mathrm{BAC}$ & $8.81 \mathrm{~b}$ & 9.06 & $7.86 \mathrm{c}$ & $7.78 \mathrm{c}$ \\
\hline pooled SEM & 0.023 & 0.023 & 0.035 & 0.042 \\
\hline model RMSE & 0.298 & 0.328 & 0.415 & 0.479 \\
\hline model P-value & 0.001 & 0.322 & 0.001 & 0.001 \\
\hline \multicolumn{5}{|l|}{ Main effect LAC } \\
\hline none & 8.72 & 9.11 & 8.33 & 8.35 \\
\hline with inclusion & 8.91 & 9.06 & 8.05 & 7.87 \\
\hline \multicolumn{5}{|l|}{ Main effect BAC } \\
\hline none & 8.88 & 9.06 & 8.43 & 8.33 \\
\hline with addition & 8.75 & 9.11 & 7.96 & 7.89 \\
\hline \multicolumn{5}{|l|}{ P-value } \\
\hline LAC & 0.001 & 0.272 & 0.001 & 0.001 \\
\hline $\mathrm{BAC}$ & 0.002 & 0.245 & 0.001 & 0.001 \\
\hline $\mathrm{LAC} \times \mathrm{BAC}$ & 0.082 & 0.335 & 0.144 & 0.001 \\
\hline
\end{tabular}

${ }^{1}$ For dietary treatment abbreviations, please refer to the Material and methods section of the text. $\mathrm{a}, \mathrm{b}, \mathrm{c}-$ within a column individual treatment means with different letters are different at $\mathrm{P}<0.05$.

\section{Discussion}

The principal intention of this study was to investigate the impact of whey lactose when fed in a combination with Lactobacillus agilis bacteria; however, the individual effects of the LAC and the bacterial additive were also essential since they were compared with those of the 'synbiotic'. 
Unlike the results of our previous experiment involving broilers kept in battery cages (Alloui and Szczurek, 2017), dietary inclusion of the 2\% LAC did not display the growth-promoting effect in the present experiment. On the other hand, in line with the findings of the aforementioned study, chickens consuming the diets with LAC produced more watery droppings, which may suggest the water-absorbent effect of ingested lactose resulting in luminal water retention (Deng et al., 2015). However, despite this they exhibited better feed-to-gain ratio during the entire experimental period, with no additive influence of a mix LAC $+\mathrm{BAC}$ on the FCR value. It is difficult to directly compare the results from different trials using lactose or dried whey and/or various probiotic bacteria because the efficacy of their application depends on many factors, among them the housing conditions. Monitoring and some research have shown, for example, the superiority of caged broilers over those reared on deep litter with regard to growth rates (Reece et al., 1971). Furthermore, there is a possibility that some health problems coupled with bacterial infections or emission of noxious gases might be reduced if broilers are removed from intimate contact with their excreta (Willis et al., 2002). Taking this into consideration, there is no opportunity to ascertain to what extent improvements in the BWG from feeding dried whey alone (in amounts equivalent to 1.4 and $2.7 \%$ lactose) found by Kermanshahi and Rostami (2006) or dried whey $(0.75 \%$ LAC in the feed) plus Pediococcus acidilactici bacteria (Radfar and Farhoomand, 2008) may have been associated with housing environment, since these authors did not specify whether the chickens were held in cages or on the litter floor. On the other hand, according to freshly published data (Ocejo et al., 2017), supplementation of maize/soybean mealbased diets with $6 \%$ dry whey powder ( $>40 \mathrm{~g}$ lactose $/ \mathrm{kg}$ of feed) failed to improve the growth performance and feed efficiency of broiler chickens kept during the 42-day rearing period in floor pens bedded with wood shaving litter.

The lack of difference in the BWG of chickens when the preparation of L. agilis was added to the basal diet (main effect $\mathrm{BAC}$ and $\mathrm{CON}$ vs. $\mathrm{CON}+\mathrm{BAC} ; \mathrm{P}>0.05$ ) contradicts the findings of Lan et al. (2003) concerning the probiotic effect of the L. agilis strain isolated from the chicken intestine. In their study, L. agilis addition resulted in the significantly increased weight gains of the chickens after 30 to 40 days of rearing. However, this discrepancy could be mainly due to the considerably higher level of L. agilis dietary addition in that study (one billion $\mathrm{CFU} / \mathrm{kg}$ of feed) than in the present experiment (90 million bacterial cells $/ \mathrm{kg}$ feed). The present data on the feed efficiency match up with the observations made by Samli et al. (2007) where birds fed E. faecium or E. faecium + dried whey had significantly improved FCR. However, Jung et al (2008) found that the inclusion of the prebiotic syrup containing $10 \%$ of lactose, the Bifidobacterium lactis-based probiotic or a combination of both had no significant effect on the body weight, FI and FCR in chickens grown over the 40-day period.

As in our previous experiment (Alloui and Szczurek, 2017), no significant differences in processing yields were found between the chickens from the '-' LAC vs. '+' LAC dietary treatments, including the LAC + BAC supplemented diet. No significant differences were found either in carcass percentage, valuable meat yields and abdominal fat deposition among broilers fed diets with or without microbiological product. The latter observation, pertaining to the lack of the influence of dietary L. agilis on abdominal fat, is in agreement with the findings of Bozkurt et al. (2009) who reported that the di- 
etary addition of a combined probiotic preparation (L. acidophilus, L. casei, E. faecium and $B$. bifidum) had no effect on abdominal fat as a $\%$ of LBW, but contrasts with the results of Kalavathy et al. (2003), who showed that supplementation of a mixture of the 12 Lactobacillus strains significantly decreased the abdominal fat content in broilers at 28,35 and 42 days of age.

In the current experiment there were no significant differences in the relative weights of the liver, spleen and bursa between the 6-week-old chickens fed the four dietary treatments from day 8 of age, with no overall effects of LAC and BAC supplements. Splenomegaly, hepatomegaly or hypertrophic bursa of Fabricius are indirect indicators of physiological disorders (e.g. immunity-related stress or infections) and these were not observed in the response to any treatment. Therefore, the obtained results suggest that the used culture of L. agilis bacteria and the $2 \%$ of whey lactose in the diet had no adverse effect on the general health status of the chickens. In agreement with the present findings, it was reported that the weights (relative or absolute) of the liver, spleen and bursa are not significantly affected by dried whey or lactose plus probiotic bacteria (El-Banna et al., 2010) or by the inclusion of probiotic products based on different LAB species (Kalavathy et al., 2003; Bozkurt et al., 2009).

Since the lactose provided in the feed or drinking water may serve as a fermentation substrate in chicken crops, the $\mathrm{pH}$ reduction of the crop ingesta observed in this experiment with broilers from the $\mathrm{CON}+\mathrm{LAC}$ and $\mathrm{CON}+\mathrm{LAC}+\mathrm{BAC}$ dietary treatments was not unanticipated. In agreement with this result, the significantly lower crop pH in 5-week-old broilers was reported by Rutkowski et al. (2005) based on the trial with inclusion of $1.5 \%$ dried whey $+E$. faecium. Furthermore, in vitro studies have shown that different strains of L. agilis bacteria are able to produce acid from a range of mono- and disaccharides including lactose (Baele et al., 2001); this seems to be the main reason for the 'acidification effect' of dietary L. agilis alone in the crop, and L. agilis + LAC in crop, ileum, and the caecum of chickens. Somewhat unexpectedly, especially in the light of the studies by McReynolds et al. (2007) who indicated no effect of increasing levels of lactose (between $1 \%$ and $4.5 \%$ of the diet) on upper intestinal $\mathrm{pH}$, in this experiment the ileal contents $\mathrm{pH}$ was significantly reduced in the chickens provided with LAC as a separate dietary supplement. One potential reason for this $\mathrm{pH}$-lowering effect of lactose observed herein is related to the caecal lumen reflux and possible migration to the ileal part of the small intestine of some bacterial species converting LAC to organic acids. It cannot be excluded, however, that this response was also associated with the ileal fermentation of LAC by an increased indigenous population of lactic acid-producing bacteria. Samli et al. (2007) documented that the treatment with dried whey supplying $28 \mathrm{~g}$ of lactose $/ \mathrm{kg}$ diet, significantly increases the total number of LAB in the chicken ileum. Although not estimated in their study, this would suggest a lower $\mathrm{pH}$ of the ileal digesta.

The results pertaining to the effect of dietary LAC on the caecal VFA followed the pattern reported from our previous study (Alloui and Szczurek, 2017). The concentrations of both the total and the undissociated form of propionate and butyrate and the undissociated form of acetate were also increased after inclusion of L. agilis alone in the diet, as was seen from the respective P-values for the BAC effect, but the only additive effect (computed significant interaction) of the L. agilis and lactose cosupplementation 
has been observed for total butyrate. Due to its stimulatory effect on the intestinal mucosal growth (Cavaglieri et al., 2003) and the ability to inhibit Salmonella invasion in the chicken caecal epithelial cells (Van Immerseel et al., 2004), butyrate is currently attracting more attention than the other VFA. According to Duncan et al. (2004), the increase in the number of lactobacilli and/or bifidobacteria in the gut correlates with the increase of butyric acid concentration. Using an in vitro system, operated with a batch bioreactor, Meimandipour et al. (2009) evidenced that the addition of L. agilis (JCM 1048) and L. salivarius ssp. salicinius (JCM 1230) into fermentation vessels inoculated with the chicken caecal content significantly increased the production of propionate and butyrate. Taking this into consideration, it seems that the present experiment suggests the potential role of the used L. agilis bacteria as probiotic microorganisms; they were found not only to generate propionic acid but also to stimulate butyrate-producing bacteria to produce butyric acid in the caeca.

In the present experiment, separate treatment with the LAC increased the amount of Bacteroides sp./Prevotella sp. but the effect of the combination of whey lactose with BAC was not potentiated in terms of the number of these bacteria. What is more, the BAC treatment led to a lower caecal Bacteroides sp./Prevotella sp. population. These results can perhaps be explained by the competition for fermentation substrates between the mixed community of caecal Bacteroides and the added L. agilis bacteria. This hypothesis is supported by a range of previous observations that both the different species of Bacteroides and the L. agilis ferment lactose (and glucose) and can produce succinic and acetic acids as the end-products of the fermentation (Patel, 1983; Lan et al., 2003). The Erec482 specific probe produced the absolute counts of the Clostridium coccoides-Eubacterium rectale group that averaged $9.08 \log _{10} \mathrm{cfu} / \mathrm{g}$ across the treatments showing the high abundance of these bacteria in the caeca of broilers aged 6 weeks, with no noticeable shift due to the LAC or 'synbiotic' (LAC + BAC) supplementations. In comparison, Zhu and Joerger (2003) reported that in 6-week-old birds they covered approximately $22 \%$ of the total caecal bacterial population by the use of the same Erec482 probe as was done herein. The Enterobacteriaceae family includes the genus Salmonella from which two serovars of the Salmonella enterica species: Typhimurium and Enteritidis are the most frequently reported pathogenic bacteria found in the food production chain, and the $S$. Typhimurium is also one of the more common serovars detected in poultry (Foley et al., 2008). The genus Escherichia, which includes the species E. coli, belongs to the same family. Even though $E$. coli is a member of the commensal intestinal flora, some $E$. coli strains have evolved pathogenic mechanisms to colonise humans and animals (Guentzel, 1996). The present results concerning the influence of the $2 \%$ dietary whey lactose alone or in combination with the preparation of L. agilis on Enterobacteriaceae FISH counts followed the same significant downward trend as seen with the number of the coliform bacteria determined in our previous experiment using the plate counting method (Alloui and Szczurek, 2017). But, interestingly, treatment with the L. agilis alone was also found to be effective in reducing the Enterobacteriaceae population. These results appear to be in line with expectations about the obtaining of a desired drop in the caecal colonisation of pathogenic Enterobacteria from inclusion of the lactose and probiotics in the poultry diets. As far 
back as 2012, Totton et al. concluded from a meta-analysis on the effects of different feed and water additives for reducing Salmonella spp. that lactose and its associated products (dried whey, lactulose and lactosucrose) have the most promising effects in reducing the prevalence and concentration of Salmonella in the broiler intestinal tract. Some recent studies have demonstrated that chickens receiving the Lactobacillaceae-based probiotic cultures alone were also protected against caecal colonisation by E. coli (Radfar and Farhoomand, 2008) or S. Typhimurium (Chen et al., 2012). The present decline in the Enterobacteriaceae FISH count due to the L. agilis supplementation seems to fit with the above observations, especially since Ehrmann et al. (2002) demonstrated that L. agilis, among other LAB, displayed an inhibitory effect on the proliferation of $E$. coli, $S$. Enteritidis, $S$. Typhimurium as indicator strains tested in an agar spot test. It has been previously demonstrated that the undissociated concentrations of VFA are strongly responsible for the decrease in viable counts of Enterobacteriaceae (van der Wielen et al., 2000). This type of action mechanism, i.e. through the increased levels of the UD VFA, has also been described for ingested lactose and has been found as an effective means for reducing the incidence of caecal Salmonella in young chickens (Hinton et al., 1990, 1991). It is worth noting here that in the present experiment both the whey lactose and the L. agilis dietary inclusions led to a 3-4-times greater concentration of undissociated propionate and to a 5-6-fold increase in the caecal UD butyrate. Especially noteworthy from the present results is that the whey lactose or L. agilis bacteria supplementation is effective in decreasing the Clostridium perfringens population in the caecum. This anticlostridial effect indicated for LAC administered alone supports the observations of Takeda et al. (1995) that lactose can significantly reduce the abundance of $C$. perfringens in the caeca of growing broilers. Also, according to McReynolds et al. (2007) a dietary addition of lactose at the $2.5 \%$ dose can greatly diminish the clinical signs of NE: all of the control birds challenged with $C$. perfringens had clinical intestinal lesions compared to only $30 \%$ of birds fed lactose in their experiment. Regarding probiotic bacteria, Decroos et al. (2004) demonstrated that different strains of lactobacilli and enterococci reduced Clostridium population in the excreta of broilers up to the age of 42 days. Moreover, the current literature suggests that the probiotic product (L. salivarius + Pedicoccus parvulus), provided via drinking water to broilers challenged with $S$. Typhimurium, is able to lessen the severities of $\mathrm{NE}$ as a secondary bacterial infection caused by $C$. perfringens in an experimental model and in a commercial field outbreak of NE (Layton et al., 2013). The significant LAC $\times$ BAC interaction detected in the present experiment suggests that the beneficial effect of whey lactose at $2 \%$ of the diet in terms of the reduced caecal count of $C$. perfringens can be amplified when used in association with the Lactobacillus agilis bacteria.

The results of this study showed that supplementation with a mix of whey lactose ( $2 \%$ in the diet) and Lactobacillus agilis bacteria does not offer the potential to create a more profound positive change in the productive performance of broilers in comparison with the endpoints from birds treated separately with whey lactose or bacterial preparation. In addition, this 'synbiotic' is incapable of avoiding the lactoserelated problem with wet droppings. However, the favourable additive effects of the simultaneous supplementation with whey lactose and the L. agilis can be expected 
on the butyric acid concentration, and on C. perfringens and Enterobacteriaceae counts in the caecal contents. Alteration in the caecal microbiota toward the exclusion of deleterious (Enterobacteriaceae) and pathogenic (C. perfringens) organisms provides support for the beneficial role of $L$. agilis when administered as a separate dietary supplement at a dose rate of 90 million viable cells $/ \mathrm{kg}$ of feed.

\section{References}

A d h i k a r i P.A., K i m W.K. (2017). Overview of prebiotics and probiotics: focus on performance, gut health and immunity - a review. Ann. Anim. Sci., 17: 949-966.

A 11 o u i M.N., S z c z u r e k W. (2017). Effects of different dietary levels of whey lactose as a prebiotic disaccharide on the productive performances and selected indices of the caecal micro-environment in broiler chickens. Ann. Anim. Sci., 17: 1107-1122.

A 11 o u i M.N., S z c zu rek W., Ś w ią t ki ew i c z S. (2013). The usefulness of prebiotics and probiotics in modern poultry nutrition: a review. Ann. Anim. Sci., 13: 17-32.

AOAC International (2000). Official methods of analysis of AOAC International. Gaithersburg, USA, 17th ed., Association of Analytical Communities.

A v i a g e n (2014). Ross Broiler Management Handbook. 0814-AVNR-032. Aviagen Inc., Huntsville, USA, pp. 131.

B a e le M., Devrie se L.A., Ha e s e brouck F. (2001). Lactobacillus agilis is an important component of the pigeon crop flora. J. Appl. Microbiol., 91: 488-491.

B o zk urt M., K u cukyilmaz K., C a tli A.U., Cin ar M. (2009). The effect of single or combined dietary supplementation of prebiotics, organic acid and probiotics on performance and slaughter characteristics of broilers. S. Afr. J. Anim. Sci., 39: 197-205.

$\mathrm{C}$ ava g $\mathrm{l}$ i er i C.R., $\mathrm{N}$ is hi y a m a A., F er nande s L.C., Curi R., Miles E.A., Calder P.C. (2003). Differential effects of short-chain fatty acids on proliferation and production of pro- and anti-inflammatory cytokines by cultured lymphocytes. Life Sci., 73: 1683-1690.

Ch en C.Y., Ts e n H.Y., L in C.L., Yu B., C h e n C.S. (2012). Oral administration of a combination of select lactic acid bacteria strains to reduce the Salmonella invasion and inflammation of broiler chicks. Poultry Sci., 91: 2139-2147.

Decroos K., Vercauteren T., Werquin G., Verstraete W. (2004). Repression of Clostridium population in young broiler chickens after administration of a probiotic mixture. Commun. Agric. Appl. Biol. Sci., 69: 5-13.

D e n g Y., M is s e lw it z B., D a i N., F o x M. (2015). Lactose intolerance in adults: biological mechanism and dietary management. Nutrients, 7: 8020-8035.

D un can S.H., L o u is P., F lin t H.J. (2004). Lactate-utilizing bacteria, isolated from human feces that produce butyrate as a major fermentation product. Appl. Environ. Microbiol., 70: 5810-5817.

Ehrmann M.A., Kurzak P., B a u e r J., Voge 1 R.F. (2002). Characterization of lactobacilli towards their use as probiotic adjuncts in poultry. J. Appl. Microbiol., 92: 966-975.

E 1 - B a n n a H.A., E 1 - Z o r b a H.Y., A t $t$ i a T.A., E 1 a t if A.A. (2010). Effect of probiotic, prebiotic and synbiotic on broiler performance. World Appl. Sci. J., 11: 388-393.

Fallani M., Rigottier-Gois L., Guilera M., Bridonneau C., Collignon A., Edw ard s C.A., C or th i e r G., D o ré J. (2006). Clostridium difficile and Clostridium perfringens species detected in infant faecal microbiota using 16S rRNA targeted probes. J. Microbiol. Methods, 67: 150-161.

F o l e y S.L., L y n n e A.M., N a y a k R. (2008). Salmonella challenges: prevalence in swine and poultry and potential pathogenicity of such isolates. J. Anim. Sci., 86 (14 Suppl.): E149-E162.

Frank s A.H., H a r m se n H.J., R a a n g s G.C., J a n s en G.J., S c hu t F., We 11 ing G.W. (1998). Variations of bacterial populations in human feces measured by fluorescent in situ hybridization with group-specific 16S rRNA-targeted oligonucleotide probes. Appl. Environ. Microbiol., 64: 3336-3345.

F u 11 e r R. (1989). Probiotics in man and animals. J. Appl. Bacteriol., 66: 365-378. 
Gu e n t z el M.N. (1996). Escherichia, Klebsiella, Enterobacter, Serratia, Citrobacter and Proteus. In: Medical microbiology, Baron S. (ed.). University of Texas Medical Branch at Galveston, USA, 4th ed., available from: http://www.ncbi.nlm.nih. gov/books/NBK8035/

H inton Jr. A., C orri er D.E., S pates G.E., Norman J.O., Z i prin R.L., B e i e r R.C., D e L o a c h J.R. (1990). Biological control of Salmonella typhimurium in young chickens. Avian Dis., 34: 626-633.

H int on Jr. A., C or r i e r D.E., Z i prin R.L., S p a te s G.E., D e L o a c h J.R. (1991). Comparison of the efficacy of cultures of cecal anaerobes as inocula to reduce Salmonella typhimurium colonization in chicks with or without dietary lactose. Poultry Sci., 70: 67-73.

Jung S.J., Houde R., B a urhoo B., Zhao X., Le e B.H. (2008). Effects of galactooligosaccharides and a Bifidobacteria lactis-based probiotic strain on the growth performance and fecal microflora of broiler chickens. Poultry Sci., 87: 1694-1699.

K a lavathy R., A bdullah N., J a l a lud in S., H o Y.W. (2003). Effects of Lactobacillus cultures on growth performance, abdominal fat deposition, serum lipids and weight of organs of broiler chickens. Br. Poultry Sci., 44: 139-144.

Kermanshahi H., R ostami H. (2006). Influence of supplemental dried whey on broiler performance and cecal flora. Int. J. Poultry Sci., 5: 538-543.

L a n P.T., B in h L.T., B e n n o Y. (2003). Impact of two probiotic Lactobacillus strains feeding on fecal Lactobacilli and weight gains in chicken. J. Gen. Appl. Microbiol., 49: 29-36.

Layton S., Hernandez-Velas co X., Chaitanya S., Xavier J., Menconi A., Latorre J., Kallapura G., Kuttappan V., Wolfenden R., Filho R., Hargis B., Tel1 e z G. (2013). The effect of a Lactobacillus-based probiotic for the control of necrotic enteritis in broilers. Food Nutr. Sci., 4 (11A): 1-7.

Manz W., Szewczyk U., Ericsson P., Amann R., Schleifer K.H., Stenström T.A. (1993). In situ identification of bacteria in drinking water and adjoining biofilms by hybridization with $16 \mathrm{~S}$ and 23S rRNA-directed fluorescent oligonucleotide probes. Appl. Environ. Microbiol., 59: 2293-2298.

McReynolds J.L., Byrd J.A., Genovese K.J., Poole T.L., Duke S.E., F arnell M.B., $\mathrm{N}$ is bet D.J. (2007). Dietary lactose and its effect on the disease condition of necrotic enteritis. Poultry Sci., 86: 1656-1661.

Me i m andipour A., Shuh a imi M., Ha ir - B ejo M., A zhar K., Kabeir B.M., Rast i B., Ya z i d A.M. (2009). In vitro fermentation of broiler cecal content: the role of lactobacilli and $\mathrm{pH}$ value on the composition of microbiota and end products fermentation. Lett. Appl. Microbiol., 49: 415-420.

Mookiah S., Sieo C.C., Ramasamy K., Abdullah N., Ho Y.W. (2014). Effects of dietary prebiotics, probiotic and synbiotics on performance, caecal bacterial populations and caecal fermentation concentrations of broiler chickens. J. Sci. Food Agric., 94: 341-348.

O c ejo M., O porto B., Juste R.A., Hurtado A. (2017). Effects of dry whey powder and calcium butyrate supplementation of corn/soybean-based diets on productive performance, duodenal histological integrity, and Campylobacter colonization in broilers. BMC Vet. Res., 13:199. DOI: 10.1186/s12917-017-1121-5.

P at el G.B. (1983). Fermentation of lactose by Bacteroides polypragmatus. Can. J. Microbiol., 29: $120-128$.

R a d far M., F a r h o o m and P. (2008). The role of probiotic and source of lactose as feed additives on performance and gut improvement in broilers. Asian J. Anim. Vet. Adv., 3: 179-182.

R e e c e F.N., D e a t o n J.W., M a y J.D., M a y K.N. (1971). Cage versus floor rearing of broiler chickens. Poultry Sci., 50: 1768-1790.

Rehman H., Vahjen W., Kohl-Paris ini A., Ijaz A., Zentek J. (2009). Influence of fermentable carbohydrates on the intestinal bacteria and enteropathogens in broilers. World's Poultry Sci. J., 65: 75-90.

R i cke S.C. (2015). Potential of fructooligosaccharide prebiotics in alternative and nonconventional poultry production systems. Poultry Sci., 94: 1411-1418.

Rutkowski A., Kaczmarek S., Józefiak D. (2005). Alternatives for flavomycin in broiler chicken nutrition. Proc. 15th European Symposium on Poultry Nutrition, Balatonfured, Hungary, 25-29.09.2005, pp. 253-255. 
Samli H.E., S enkoylu N., K oc F., Kanter M., Agma A. (2007). Effects of Enterococcus faecium and dried whey on broiler performance, gut histomorphology and intestinal microbiota. Arch. Anim. Nutr., 61: 42-49.

Sghir A., Gramet G., Suau A., R ochet V., P o chart P., D oré J. (2000). Quantification of bacterial groups within human fecal flora by oligonucleotide probe hybridization. Appl. Environ. Microbiol., 66: 2263-2266.

Taked a T., Fuk at a T., Mi y a moto T., S a s a K K., B a b a E., A rakaw a A. (1995). The effects of dietary lactose and rye on caecal colonisation of Clostridium perfringens in chicks. Avian Dis., 39: 375-381.

Totton S.C., Farrar A.M., Wilkins W., Bucher O., Waddell L.A., Wilhe lm B.J., R a j i ć A. (2012). The effectiveness of selected feed and water additives for reducing Salmonella spp. of public health importance in broiler chickens: a systematic review, meta-analysis, and metaregression approach. Prev. Vet. Med., 106: 197-213.

van der Wi elen P.W.J.J., B i es terveld S., N otermans S., H of s tra H., Urling s B.A.P., Van Knapen F. (2000). Role of volatile fatty acids in development of the cecal microflora in broiler chickens during growth. Appl. Environ. Microbiol., 66: 2536-2540.

Van Immerseel F., De Buck J., De Smet I., Pasmans F., Haesebrouck F., $\mathrm{D} \mathrm{u}$ c a t e 11 e R.. (2004). Interactions of butyric acid and acetic acid-treated Salmonella with chicken primary cecal epithelial cells in vitro. Avian Dis., 48: 384-391.

Vicente J., Wolfenden A., Torres-Rodriguez A., Higgins S., Tellez G., Har$\mathrm{g}$ is B. (2007). Effect of a Lactobacillus species-based probiotic and dietary lactose prebiotic on turkey poult performance with or without Salmonella enteritidis challenge. J. Appl. Poultry Res., 16: $361-364$.

Wi 11 is W.L., M u r ray C., Ta 1 b o t t C (2002). Campylobacter isolation trends of cage versus floor broiler chickens: a one-year study. Poultry Sci., 81: 629-631.

Wyszyńska A., Kobierecka P., B ardowski J., Jagusztyn-Krynicka E.K. (2015). Lactic acid bacteria - 20 years exploring their potential as live vectors for mucosal vaccination. Appl. Microbiol. Biotechnol., 99: 2967-2977.

Z hu X.Y., J o e rger R.D. (2003). Composition of microbiota in content and mucus from cecae of broiler chickens as measured by fluorescent in situ hybridization with group-specific, 16S rRNAtargeted oligonucleotide probes. Poultry Sci., 82: 1242-1249.

Received: 21 VIII 2017

Accepted: 13 XII 2017 